\title{
Toxic Shock Syndrome Toxin 1 Induces Immune Response via the Activation of NLRP3 Inflammasome
}

\author{
Lianci Peng ${ }^{1,+}$, Jiali Jiang ${ }^{1,2,+}$, Tingting Chen ${ }^{1}$, Dongyi Xu ${ }^{1}$, Fengqing Hou ${ }^{1}$, Qingyuan Huang ${ }^{1}$, Yuanyi Peng ${ }^{1}$, \\ Chao Ye ${ }^{1}$, Dong-Liang Hu ${ }^{1,3, *}$ and Rendong Fang ${ }^{1,4, *}$
}

1 Joint International Research Laboratory of Animal Health and Animal Food Safety, College of Veterinary Medicine, Southwest University, Chongqing 400715, China; penglianci@swu.edu.cn (L.P.); jiangjiali202012@163.com (J.J.); cttctt@outlook.com (T.C.); xudongyi29@gmail.com (D.X.); houfengqing08@163.com (F.H.); huangqingyuan2020@163.com (Q.H.); pyy2002@sina.com (Y.P.); yechao123@swu.edu.cn (C.Y.)

2 Chongqing Animal Disease Prevention and Control Center, Chongqing 401120, China

3 Department of Zoonoses, Kitasato University School of Veterinary Medicine, Towada 034-8628, Japan

4 Immunology Research Center, Medical Research Institute, Southwest University, Chongqing 402460, China

* Correspondence: hudl@vmas.kitasato-u.ac.jp (D.-L.H.); rdfang@swu.edu.cn (R.F.); Tel.: +86-23-68251196 (R.F.)

$+\quad$ Lianci Peng and Jiali Jiang contributed equally to this work.

check for

updates

Citation: Peng, L.; Jiang, J.; Chen, T.; Xu, D.; Hou, F.; Huang, Q.; Peng, Y.; Ye, C.; Hu, D.-L.; Fang, R. Toxic Shock Syndrome Toxin 1 Induces Immune Response via the Activation of NLRP3 Inflammasome. Toxins 2021, 13, 68. https://doi.org/10.3390/ toxins13010068

Received: 10 December 2020

Accepted: 12 January 2021

Published: 18 January 2021

Publisher's Note: MDPI stays neutral with regard to jurisdictional claims in published maps and institutional affiliations.

Copyright: (c) 2021 by the authors. Licensee MDPI, Basel, Switzerland. This article is an open access article distributed under the terms and conditions of the Creative Commons Attribution (CC BY) license (https:// creativecommons.org/licenses/by/ $4.0 /)$.

\begin{abstract}
Staphylococcus aureus is a Gram-positive opportunistic pathogen which causes infections in a variety of vertebrates. Virulence factors are the main pathogenesis of S. aureus as a pathogen, which induce the host's innate and adaptive immune responses. Toxic shock syndrome toxin 1 (TSST-1) is one of the most important virulence factors of S. aureus. However, the role of nucleotidebinding oligomerization domain-like receptor family pyrin domain containing 3 (NLRP3) in TSST1-induced innate immune response is still unclear. Here, purified recombinant TSST-1 (rTSST-1) was prepared and used to stimulate mouse peritoneal macrophages. The results showed that under the action of adenosine-triphosphate (ATP), rTSST- 1 significantly induced interleukin- $1 \beta$ (IL-1 $\beta)$ and tumor necrosis factor- $\alpha$ (TNF- $\alpha$ ) production in mouse macrophages and the production was dose-dependent. In addition, rTSST-1+ATP-stimulated cytokine production in macrophage depends on the activation of toll like receptor 4 (TLR4), but not TLR2 on the cells. Furthermore, the macrophages of $\mathrm{NLRP}^{-/}{ }^{-}$mice stimulated with rTSST-1+ATP showed significantly low levels of IL-1 $\beta$ production compared to that of wild-type mice. These results demonstrated that TSST-1 can induce the expression of inflammatory cytokines in macrophages via the activation of the TLR4 and NLRP3 signaling pathways. Our study provides new information about the mechanism of the TSST-1-inducing host's innate immune responses.
\end{abstract}

Keywords: Staphylococcal toxins; toxic shock syndrome toxin 1; inflammasome; interleukin-1 $\beta$

Key Contribution: Our study reveals for the first time that inflammasome NLRP3 mediates the superantigen toxin TSST-1-induced inflammatory response, contributing to the development of therapeutics against $S$. aureus infection.

\section{Introduction}

Staphylococcus aureus (S. aureus) is a common Gram-positive extracellular pathogen causing severe infections, such as abscesses, osteomyelitis, septic arthritis, pneumonia and endocarditis [1]. In the last few years, S. aureus pathogenesis to the host has been identified by different virulence factors, such as surface proteins (protein A), pore-forming toxins (e.g., Panton-Valentine Leukocidin (PVL)), $\alpha$-hemolysin ( $\alpha$-toxin) and superantigen toxins [2-4]. During S. aureus infection, these virulence factors can induce innate immune responses and produce inflammatory or pro-inflammatory cytokines. However, among these virulence factors, the interaction between Staphylococcal superantigen toxins (SAgs) and host innate immunity is less studied. 
Superantigens are the products of some bacterial exotoxins or retroviruses with a variety of immune activities [5]. Toxic shock syndrome toxin 1 (TSST-1) is one of SAgs [6]. TSST-1 is an important virulence factor of S. aureus and causes toxic shock syndrome (TSS) [7]. This disease can be diagnosed by fever, rash and desquamate, hypotension and organ impairment, leading to the high mortality [8]. TSST-1 directly crosslinks the major histocompatibility complex class II (MHC-II) molecules on antigen-presenting cells to $\mathrm{T}$ cell receptors (TCRs), resulting in the activation of $\mathrm{T}$ cells and macrophages with high production of cytokines $[9,10]$. Some studies showed that TSST- 1 can enhance the lipopolysaccharide (LPS)-induced production of gamma interferon (IFN- $\gamma$ ), IL-1 $\beta$, IL-6, IL-10 in human peripheral blood monocytes and rabbit spleen cells [11,12]. TSST- 1 also increases LPS-induced IL-1 secretion in macrophages and TNF- $\alpha$ and IL-12 secretion in dendritic cells [13-15]. However, the mechanism of TSST-1-induced these inflammatory cytokines in the host cells is still unclear.

Inflammasome is a multiprotein complex that consists of apoptosis-associated specklike protein containing a caspase-activating and recruitment domain (ASC), Nod-like receptors (NLRs) and pro-caspase-1. So far, inflammasome family members contain NLRP1, NLRP3, NLRC4, NLRP6, NLRP7, NLRP12 and absent in melanoma 2 (AIM2) [16]. These inflammasomes can be activated by different microbial stimuli to release inflammatory cytokines IL-1 $\beta$ and IL-18, which play an important role in the host's innate immunity against microbial infection [17]. For example, NLRC4 is assembled in response to the flagellin of Salmonella typhimurium and Legionella pneumophila, while AIM is the receptor of intracellular bacterial DNA such as Listeria monocytogenes [18-20]. Among these inflammasomes, NLRP3 is one of the most extensively studied inflammasomes. The NLRP3 pathway can be activated by different bacteria, such as Streptococcus pneumoniae, Pasteurella multocida, Corynebacterium pseudotuberculosis and S. aureus etc. [21-24].

The classic activation pathway of NLRP3 needs two signals. The first signal is mainly triggered by bacteria or pathogenic molecules such as lipoprotein and LPS, which activate the Nuclear Factor kappa-light-chain-enhancer of the activated B cell (NF- $\mathrm{kB}$ ) signaling pathway through TLR2 or TLR4, leading to production of pro-IL-1 $\beta$ and pro-IL-18, and the transcriptional and post-translational modification of NLRP3 [25]. A second activation signal, such as a bacterial toxin or adenosine-triphosphate (ATP), activates NLRP3 by $\mathrm{K}^{+}$outflow and then causes the recruitment of ASC, followed the activation of caspase-1 [26-28]. Activated caspase- 1 cleaves off pro-IL-1 $\beta$ and pro-IL-18, allowing them to be processed into mature IL-1 $\beta$ and IL-18, eventually resulting in their secretion to the extracellular environment [29]. It has been reported that $\alpha$-hemolysin and the PVL of S. aureus toxins induced IL-1 $\beta$ via the activation of NLRP3 [30,31]. However, it is not clear whether TSST-1 can also activate the NLRP3 inflammasome like $S$. aureus other toxins.

In this study, we expressed and purified TSST-1, then investigated the role of TSST-1 in activation of the NLRP3 inflammasome in mouse primary macrophages. Under the action of ATP, mouse peritoneal macrophages were activated by TSST- 1 via the activation of NLRP3, causing the maturation and release of IL-1 $\beta$. Our study provides a better understanding on the interaction of TSST- 1 and the host immunity, which contributes to the development of therapeutics against $S$. aureus infection.

\section{Results}

\subsection{Expression and Purification of Recombinant TSST-1}

Recombinant TSST-1 had been demonstrated to show similar activity to natural toxins purified from S. aureus [1]. In this study, recombinant TSST-1 (rTSST-1) was expressed and purified using an Escherichia coli expression system. The purity and molecular size of the recombinant toxins were determined by coomassie-blue-stained SDS-PAGE (Figure 1A). The concentration of endotoxins in the final purified rTSST- $1\left(0.406 \mathrm{mg} \cdot \mathrm{mL}^{-1}\right)$ was less than $0.001 \mathrm{EU} \cdot \mathrm{mL}^{-1}$. 

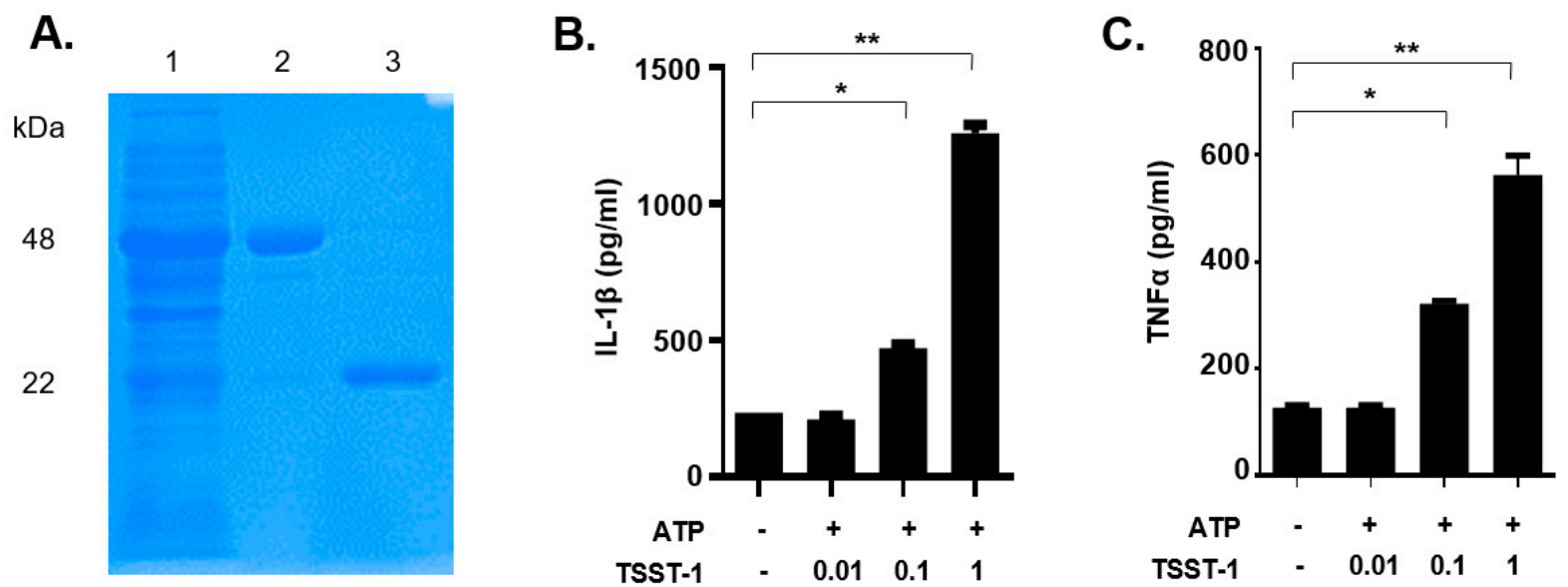

Figure 1. Purified rTSST-1-induced IL-1 $\beta$ and TNF- $\alpha$ expression in macrophages under the action of ATP. (A) The recombinant protein GST-TSST-1 was purified by Glutathione SepharoseTM 4B and digested by PreScission Protease. Lane (1): supernatant after the cleavage; lane (2): GST-TSST-1; lane (3): purified rTSST-1. Different concentrations of the purified rTSST were used to stimulate mouse macrophages under the action of $2 \mathrm{mM}$ ATP. After stimulation, cell supernatants were collected and cytokines IL-1 $\beta(\mathbf{B})$ and TNF- $\alpha(\mathbf{C})$ were determined by ELISA. The data are represented as mean \pm SD. of three independent experiments for each group $(n=3)$. ${ }^{*} p<0.05 ;{ }^{* *} p<0.01$.

\section{2. $r$ TSST-1-Induced IL-1 $\beta$ and TNF- $\alpha$ Expression in Macrophages under the Action of ATP}

To examine whether the rTSST-1 can induce inflammatory responses in mouse macrophages, rTSST- $1\left(0.01,0.1\right.$ and $\left.1 \mu \mathrm{g} \cdot \mathrm{mL}^{-1}\right)$ was used to stimulate cells under the action of ATP. After stimulation, mature IL- $1 \beta$ and TNF- $\alpha$ in the supernatants were detected by enzyme linked immunosorbent assay (ELISA). The results showed that both productions of IL- $1 \beta$ and TNF- $\alpha$ induced by rTSST- 1 were dose-dependent under ATPmediated activation of macrophages (Figure 1B,C). Notably, the secretion of IL-1 $\beta$ was not affected by TSST-1 priming only, but was clearly enhanced after ATP stimulation (Figure 2A,B). However, TNF- $\alpha$ production was highly induced by TSST-1 and it was not affected by ATP (Figure 2B). These results indicate that IL-1 $\beta$ expression is required by the ATP-mediated activation of macrophages. It has been reported that LPS and ATP can activate inflammasomes, leading to inflammatory cytokine expression. To confirm the effect of TSST-1-induced cytokine production not due to the contamination of LPS, we also analyzed the cytokine production induced by different concentrations of LPS and ATP. The results showed that a high concentration (higher than $0.1 \mathrm{EU} \cdot \mathrm{mL}^{-1}$ ) of LPS induced IL-1 $\beta$ and TNF- $\alpha$ expression, but doses of LPS less than $0.01 \mathrm{EU} \cdot \mathrm{mL}^{-1}$ did not induce the inflammatory cytokine expression in the cells (Figure 2C,D). The LPS concentration in our final dose of rTSST- 1 was less than $10^{-3} \mathrm{EU} \cdot \mathrm{mL}^{-1}$, indicating that the cytokine production induced by rTSST- 1 is due to the activation of rTSST- 1 itself, rather than the contamination of LPS. 
A.

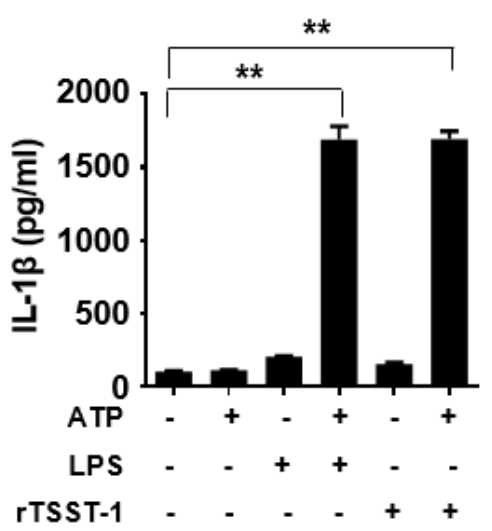

C.

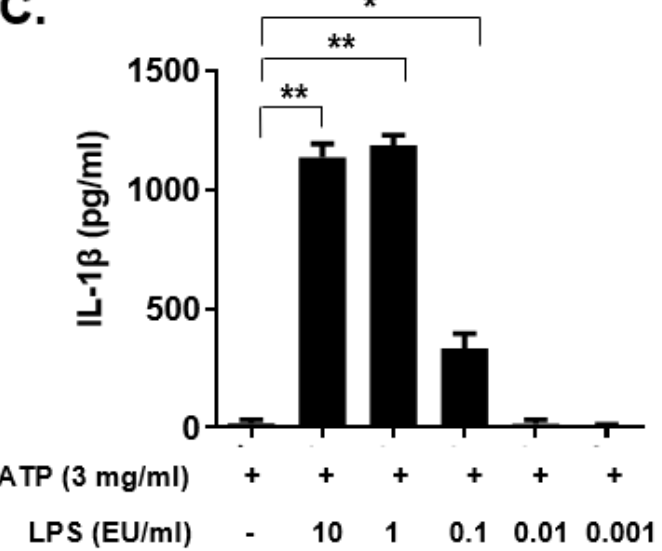

B.

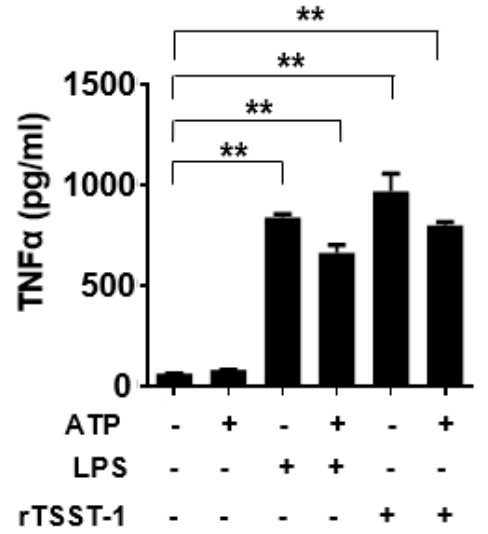

D.

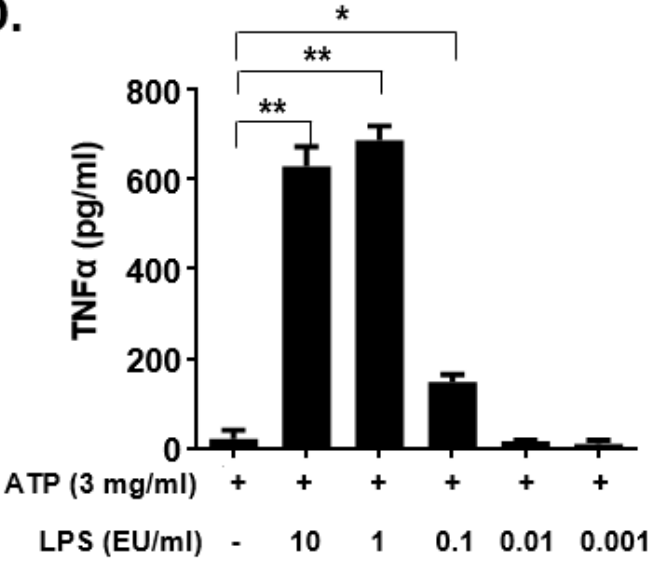

Figure 2. IL-1 $\beta$ and TNF- $\alpha$ expression in macrophages induced by rTSST-1 and LPS. The macrophages were stimulated with rTSST-1 or LPS, with or without the action of ATP. After stimulation, cell supernatants were collected and cytokines were determined by ELISA. The expression of IL-1 $\beta$ (A) and TNF- $\alpha$ (B) in LPS- or rTSST-1-stimulated macrophages. The expression of IL-1 $\beta$ (C) and TNF- $\alpha$ (D) in different concentrations of LPS-stimulated macrophages. The data are represented as mean $\pm \mathrm{SD}$ of three independent experiments for each group $(n=3) .{ }^{*} p<0.05 ;{ }^{* *} p<0.01$.

\section{3. rTSST-1-Induced IL-1 B Secretion in Macrophages Is Dependent on TLR4 but Not on TLR2}

TLR2 and TLR4 are cell surface receptors involved in the detection of different microbeassociated molecular patterns (MAMPs). The activation of TLR2 and TLR4 can activate cells, resulting in the production of inflammatory cytokines. To evaluate the role of TLR2 and TLR4 in rTSST-1+ATP-induced inflammatory response, peritoneal macrophages from wild type (WT), TLR2 ${ }^{-/-}$and TLR $4^{-/-}$mice were stimulated with rTSST-1+ATP, then inflammatory cytokines including IL- $1 \beta$ and TNF- $\alpha$ were detected by ELISA. After rTSST$1+$ ATP stimulation, both IL- $1 \beta$ and TNF- $\alpha$ secretion in macrophages of TLR $4^{-/-}$mice were markedly abolished while cytokine secretion was not affected in the macrophages of TLR2 ${ }^{-/-}$and WT mice (Figure 3A,B). These results demonstrate that TLR4 but not TLR2 was involved in the secretion of IL-1 $\beta$ and TNF- $\alpha$ induced by rTSST- $1+$ ATP. To further determine the involvement of TLR4 in IL-1 $\beta$ secretion induced by rTSST- $1+$ ATP in macrophages, we used rTSST-1+ATP to stimulate the peritoneal macrophages of WT mice and TLR4 $4^{-/}$mice, respectively. After $3 \mathrm{~h}, 6 \mathrm{~h}$, and $9 \mathrm{~h}$ stimulation, cell lysates were collected and RNA was extracted. A real-time fluorescent quantitative PCR test was performed. The result showed that IL- $1 \beta$ mRNA was not induced by rTSST- $1+$ ATP in the macrophages of TLR4 ${ }^{-/-}$mice, indicating that TLR4 also affects the secretion of IL- $1 \beta$ at the transcription level (Figure 3C). 

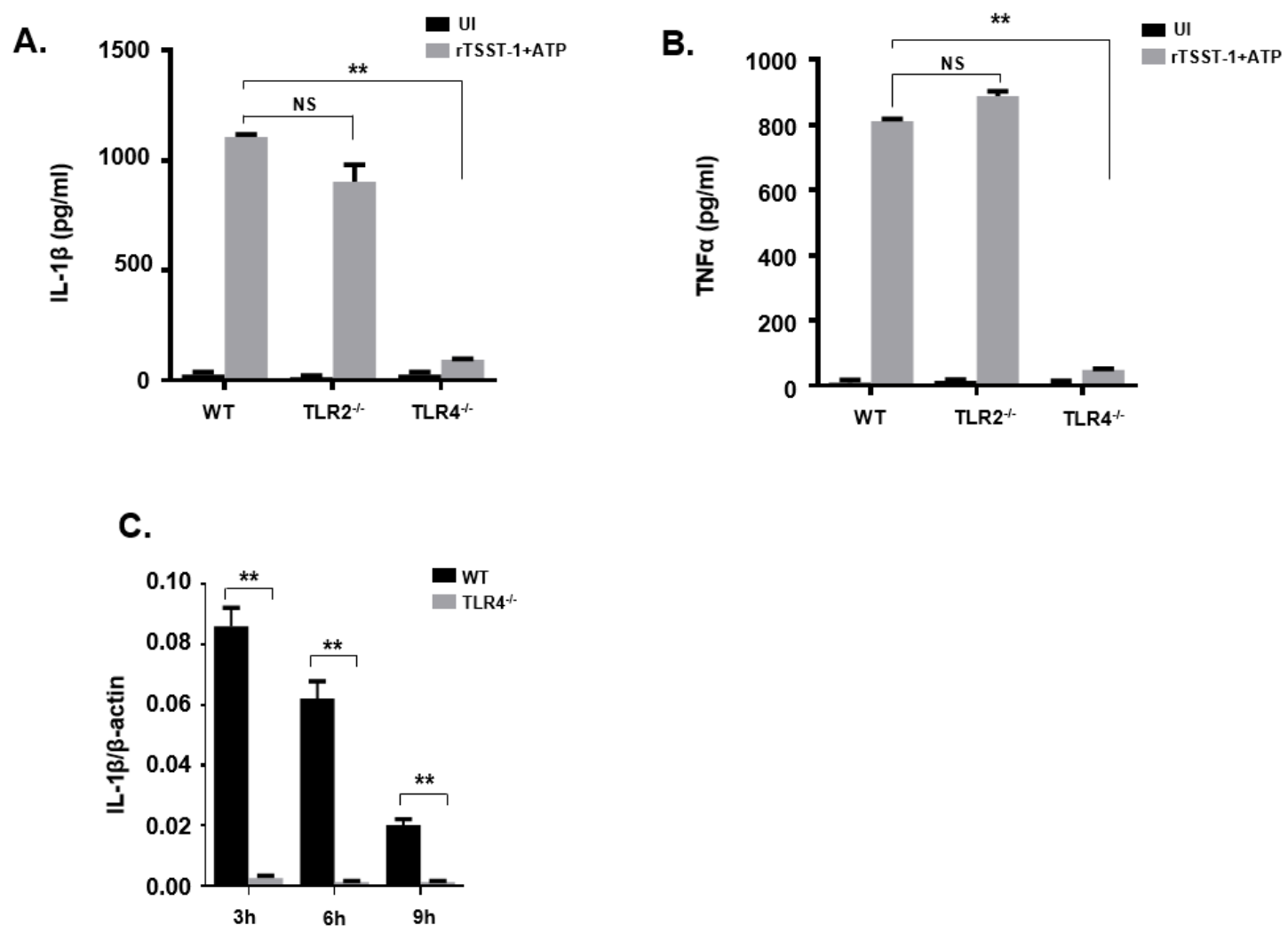

Figure 3. rTSST-1-induced inflammatory cytokine expression in macrophages from wild mice and gene knockout mice. Macrophages from C57BL/ 6 wild type (WT), TLR2 ${ }^{-/-}$and TLR4 ${ }^{-/-}$mice were unstimulated (UI) or stimulated with $1 \mathrm{ng} \cdot \mathrm{mL}^{-1} \mathrm{rTSST}-1$ and $2 \mathrm{mM}$ ATP. After indicated time stimulation, the expression of IL- $1 \beta(\mathbf{A})$ and TNF- $\alpha(\mathbf{B})$ in the cell supernatants were determined by ELISA and the mRNA expression of IL-1 $\beta(C)$ in the cells was determined by quantitative polymerase chain reaction (qPCR). The data are represented as mean $\pm \mathrm{SD}$ of three independent experiments for each group $(n=3) . * *<0.01$.

\subsection{NLRP3 Inflammasome Was Involved in IL-1 $\beta$ Maturation and Secretion in rTSST-1-Stimulated Macrophages}

To investigate the exact mechanism of rTSST-1-induced IL-1 $\beta$ secretion in macrophages, we hypothesized that rTSST-1 induced IL- $1 \beta$ production through inflammasome activation. Macrophages from WT, Caspase- $1^{-/-}, \mathrm{ASC}^{-/-}$and $\mathrm{NLRP3}^{-/-}$mice were stimulated with rTSST-1+ATP, and the secretion of IL- $1 \beta$ and TNF- $\alpha$ in the cell supernatants were determined by ELISA (Figure 4A,B). Furthermore, cell lysates and supernatants were detected by Western blot. The ELISA results showed that IL-1 $\beta$ production was dramatically reduced in Caspase- $1^{-/-}, \mathrm{ASC}^{-/-}$and $\mathrm{NLRP3}^{-/-}$macrophages (Figure 4A) but TNF- $\alpha$ expression was not affected (Figure 4B), indicating that rTSST-1-induced IL-1 $\beta$ secretion requires assembly of inflammasome proteins. Caspase-1 is a key factor in the maturation and secretion of IL- $1 \beta$. The Western blot results showed that the mature Caspase- 1 (Casp1 p20) was significantly expressed in the cell supernatant of WT mice macrophages, while there was no activated Caspase-1 expression detected in the cell supernatant of knockout mice, indicating that the activation of Caspase-1 depends on ASC and NLRP3. Similarly, the IL-1 $\beta$ expression of WT mice was significantly higher than in knockout mice. However, due to the activation of Caspase-1, a large number of Caspase- 1 in the cell lysates was lysed into P20 fragments and secreted into the supernatants, resulting in less pro-Caspase-1 expression in the lysates of stimulated cells than those of the unstimulated cells (Figure 4C). 

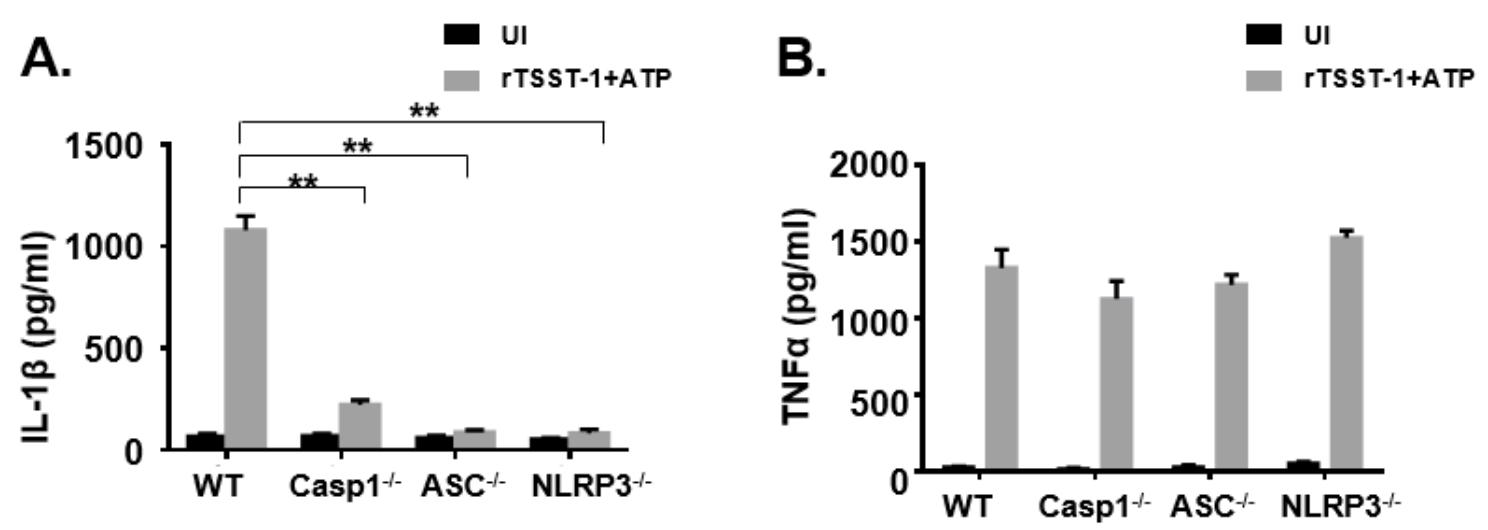

C. UI TSST-1+ATP

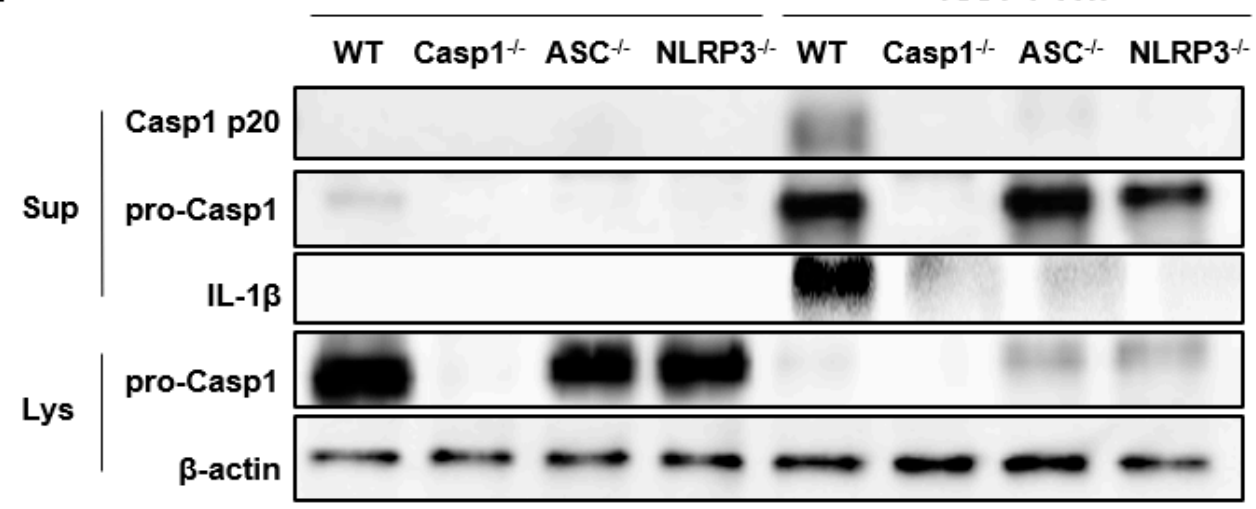

Figure 4. rTSST-1-induced IL-1 $\beta$ expression is dependent on the activation of NLRP3 inflammasome. Macrophages from WT, Casp1 $1^{-/-}, \mathrm{ASC}^{-/-}$and NLRP3 ${ }^{-/-}$mice were unstimulated (UI) or stimulated with $1 \mathrm{ng} \cdot \mathrm{mL}^{-1} \mathrm{rTSST}-1$ and $2 \mathrm{mM}$ ATP. After stimulation, expression of IL-1 $\beta$ (A) and TNF- $\alpha(\mathbf{B})$ in the supernatant were measured by ELISA. Caspase-1, pro-Caspase- 1 and IL-1 $\beta$ in the cells were detected by Western blot (C). The data are represented as mean \pm SD. of three independent experiments for each group $(n=3) .{ }^{* *} p<0.01$.

\section{Discussion}

TSST-1 is an important virulence factor of $S$. aureus strains. It can cause TSS, which is a serious infectious disease with rapid progression and high mortality. In order to understand the role of TSST- 1 in host defense against $S$. aureus infection, we successfully obtained the high purity rTSST- 1 toxin by using the E. coli prokaryotic expression system and investigated the effects of rTSST-1-induced inflammatory cytokine productions in the macrophages of mice. Our results showed for the first time that rTSST- 1 can strongly induce inflammatory cytokine production in the macrophages of mice with participation of extrinsic ATP, and the inductive activities are dependent on the TLR4 and NLRP3 signaling pathway. It has been reported that multiple toxins from S. aureus, including $\alpha$-Hemolysin (Hla), panton-valentine leukocidin (PVL) and leukocidin A/B (LukAB), were shown to activate the intracellular NLRP3 inflammasome in macrophages, monocytes and neutrophils, leading to pro-inflammatory cytokine release [32]. The well-known staphylococcal toxins that activate inflammasomes were pore-forming-toxins, so the activation of inflammasomes was thought to be limited to the pore-forming-toxins. In the present study, our results showed for the first time that TSST-1, a non-pore-forming toxin of S. aureus, can activate inflammasomes and induce strong inflammatory responses in macrophages in the participation of extrinsic ATP.

TSST-1 is a typical bacterial superantigenic toxin that can directly bind to the major histocompatibility complex class II molecules on macrophages or dendritic cells and T 
cell receptors $[26,27]$. This subsequently leads to a large proliferation of $\mathrm{T}$ cells and high production of proinflammatory cytokines including interleukin (IL)-2 and interferon (IFN)$\gamma[26,27]$ which causes life-threatening TSS. Narita et al. reported that vaccination with a non-superantigenic mutant TSST-1 (mTSST-1) protected mice against $S$. aureus infection dependent on increased number of IL-17A-produced cells [33]. They found that rTSST-1 stimulation induced the expression of IFN- $\gamma$ and IL-17 in spleen cells from mTSST-1vaccinated mice, and the expression of cytokines was dependent on its superantigenic activity. Cui et al. reported that immunization with glutathione S-transferase (GST)mTSST-1 induced TSST-1-neutralizing antibody production, and combination of TSST-1 with the antibody from GST-mTSST-1-immunized mice neutralized the superantigenic activity of TSST- 1 , resulting in the reduction of IFN- $\gamma$ and TNF- $\alpha$ production in spleen cells of mice [34]. These results indicated that TSST-1 could induce adaptive immune responses, neutralizing antibody production. In this experiment, rTSST-1 could directly induce macrophages to produce IL- $1 \beta$ and TNF- $\alpha$ under the action of ATP, suggesting that superantigenic activity did not mediate TSST-1-induced inflammatory cytokine production. These studies indicate that TSST- 1 can be developed as a novel molecular target for future adjuvant therapy to treat $S$. aureus infections.

Some TLRs are on the surface of cell membrane and detect different microbe-associated molecular patterns (MAMPs). After the activation of TLR induced by microbial molecules, interleukin-1 receptor-related kinases and TNF receptor-related factors are activated through the MyD88 pathway, leading to the expression of pro-IL-1 $\beta$, pro-IL-18 and NLRP3 at the transcriptional level through the activation of NF- $\mathrm{kB}$ signaling pathway. In our study, we observed that the secretion of IL-1 $\beta$ was significantly decreased in TLR4 ${ }^{-1-}$ macrophages stimulated with TSST-1+ATP, but it was not affected in TLR2 ${ }^{-/}$macrophages, indicating that TLR4 instead of TLR2 is necessary for IL- $1 \beta$ secretion.

However, unlike other toxins of $S$. aureus, such as PVL, which directly induces the release of IL- $1 \beta$ [30], only TSST- 1 did not induce the release of IL- $1 \beta$ in this study, which indicates that TSST- 1 is different from the pore-forming-toxins of $S$. aureus. In order to secrete IL- $1 \beta$, TSST- 1 as primary stimuli induced the synthesis of pro-IL- $1 \beta$ and provided signals for secondary stimuli ATP to enhance immune response. It has been reported that secondary stimuli can induce cell necrosis with the activation of caspase-1, leading to IL-1 $\beta$ secretion [35]. Our study indicates that only TSST- 1 did not induce cell necrosis and provide the important signal for the production of IL- $1 \beta$.

In conclusion, our study investigated the TSST-1-induced maturation and secretion of IL-1 $\beta$ via the TLR4/NLRP3 pathway in macrophages. Our results showed that in response to TSST-1+ATP stimulation, the NLRP3 inflammasome is assembled and caspase- 1 is activated in macrophages in vitro, indicating that the NLRP3 inflammasome is critically involved in this process. Even though our study is limited to cell level, the knockout mice used in this study provide a useful tool for investigating the role of inflammasomes in host defense against microbial infection. The role of the NLRP3 inflammasome in TSST-1-host interactions may need to be studied in vivo using inflammasome component knockout mice in the future. Our study was the first to show a pathophysiological link between staphylococcal superantigenic toxins and the NLRP3 inflammasome, providing a new therapeutic strategy for TSST-1-induced inflammatory diseases.

\section{Materials and Methods}

\subsection{Toxins}

The recombinant plasmid with the tst-1 gene, pGEX-TSST- 1 was constructed and prepared as the methods described previously [34]. The pGEX-TSST-1 was transformed into Escherichia coli BL21. After overnight culture, the bacterial cells were diluted 1:100 in $250 \mathrm{~mL}$ of LB (LAND BRIDGE, Beijing, China) medium containing $100 \mu \mathrm{g} \cdot \mathrm{mL}^{-1}$ ampicillin (Solarbio, Beijing, China). E. coli cells were grown until optical density was reached $(0.5-0.8$ at $600 \mathrm{~nm})$. Isopropyl-1-thio-b-d-galactopyranoside $\left(0.2 \mathrm{mmol} \cdot \mathrm{L}^{-1}\right)$ at $16^{\circ} \mathrm{C}$ was added to induce the expression of recombinant proteins. After overnight culture, bacterial 
pellets were collected and resuspended in sterilized PBS. GST-rTSST-1 was purified using the Glutathione Sepharose 4B (GE Healthcare Life Sciences, Marlborough, MA, USA) as previous studies described [1,34]. After endotoxin removal, the concentration of LPS in the purified proteins was less than $10^{-3} \mathrm{EU} \cdot \mathrm{mL}^{-1}$. Eventually, the purified proteins were determined by Bradford assay (Bio-Rad, Hercules, CA, USA) and analyzed by SDS-PAGE.

\subsection{Macrophages}

Wild type C57BL/ 6 mice, TLR2 ${ }^{-/-}$mice and TLR4 ${ }^{-/-}$mice with the C57BL/6 background were purchased from the Chongqing Academy of Chinese Materia Medical (Chongqing, China). Caspase- $1^{-/-}, \mathrm{ASC}^{-/-}$, and $\mathrm{NLRP3}^{-/-}$mice with the C57BL/6 background were kindly provided by Feng Shao from the National Institute of Biological Sciences, Beijing, China. All mice were maintained under specific-pathogen-free conditions and used at 8-10 weeks old. The mice were intraperitoneally injected with $2 \mathrm{~mL} 4 \%$ thioglycollate medium (Eiken Chemical, Tokyo, Japan), then 3-4 days later, peritoneal exudate cells (PECs) were collected by peritoneal lavage as described before [9]. Cell culture prior to stimulation was described in our previous study [22]. All of the animal experiments were approved by the Ethics Committee of Southwest University and carried out in accordance with the laboratory animal care principles of the National Institutes of Health, China.

\subsection{Enzyme Linked Immunosorbent Assay (ELISA)}

The macrophages were stimulated with rTSST- 1 at a concentration of $0.01 \mu \mathrm{g} \cdot \mathrm{mL}^{-1}$, $0.1 \mu \mathrm{g} \cdot \mathrm{mL}^{-1}, 1 \mu \mathrm{g} \cdot \mathrm{mL}^{-1}$ and cultured at $37^{\circ} \mathrm{C}$ in a humidified $5 \% \mathrm{CO}_{2}$ environment for $3 \mathrm{~h}$. Then, ATP ( $2 \mathrm{Mm}$; Roche Diagnostics $\mathrm{GmbH}$, Mannheim, Germany) was added to the cells, which were then incubated for an additional $18 \mathrm{~h}$. After incubation, the cell-free culture supernatants were collected to measure the concentration of cytokines (IL-1 $\beta$ and TNF- $\alpha$ ) using ELISA kits (eBioscience, San Diego, CA, USA).

\subsection{Real-Time Fluorescent Quantitative PCR}

The macrophages were stimulated with rTSST-1 $\left(1 \mu \mathrm{g} \cdot \mathrm{mL}^{-1}\right)+$ ATP $(2 \mathrm{mM})$ for 3, 6 and $9 \mathrm{~h}$. After stimulation, total RNA was extracted using the RNA pre-pure Kit (TIANGEN, Beijing, China) according to the manufacturer's instructions. Then RNase-free DNase (TIANGEN) was added to RNA $(0.2 \mu \mathrm{g})$ to remove the DNA, after which the 250R iScript advanced cDNA Synthesis kit (Bio-rad) was used to obtain cDNA. Quantitative real-time RT-PCR was performed on a Bio-rad CFX 96 (Hercules, CA, USA) using an soFast Eva Green Super-Mix (Bio-rad) according to the manufacturer's instructions. The primers for quantitative real-time RT-PCR were as follows: IL- $1 \beta, 5^{\prime}$-GAAATGCCACCTTTTGACAGTG-3' (forward) and $5^{\prime}$-TGGATGCTCTCATCAGGACAG- $3^{\prime}$ (reverse); $\beta$-actin, $5^{\prime}$-TGGAATCC TGTGGCATCCATGAAAC- $3^{\prime}$ (forward) and $5^{\prime}$-TAAAACGCAGCTCAGTAACAGTCCG-3' (reverse). The relative expression was analyzed against the expression level of $\beta$-actin.

\subsection{Western Blot Analysis}

The cells were cultured on 12-well plates $\left(1 \times 10^{6}\right.$ cells/well $)$ in RPMI 1640 with $10 \%$ FCS for $2 \mathrm{~h}$. After washing, the cells were stimulated with TSST-1 in Opti-MEM (Invitrogen) as described above. Cell supernatants were collected after $24 \mathrm{~h}$ stimulation and the cells were lysed using a radioimmune precipitation assay (RIPA) buffer (Beyotime, Beijing, China). The protein concentrations were measured using a BCA Protein Assay Kit (Beyotime, Beijing, China) and 12-15\% SDS-PAGE gel was used to analyze the proteins in the samples, which were then transferred to a polyvinylidene difluoride (PVDF) membrane to detect the target protein. After this, the membranes were blocked with $5 \%$ nonfat milk and immunoblotted with the appropriate antibody, and protein bands were detected using the ECL detection reagent (Beyotime, Beijing, China). Different antibodies were used in this study including Biotinylated anti-mouse IL-1 $\beta$ (AdipoGen, San Diego, CA, USA), Anti-Caspase-1 (p20) (AdipoGen), Anti-Caspase-1 (p45) (AdipoGen), HRP-conjugated 
mouse anti-goat or anti-mouse IgG (Beijing, China). Anti-actin was used as a loading control for the cell lysates.

\subsection{Statistical Analysis}

The statistical analysis was performed using GraphPad Prism software and the data were represented as mean \pm SD of three independent experiments for each group $(n=3)$. Student's $t$-test and ANOVA were used to analyze the significant differences between the two groups or three groups, respectively. Statistical significance was defined as $p$ value $\left({ }^{*} p<0.05\right.$ and $\left.^{* *} p<0.01\right)$.

Author Contributions: L.P., J.J., T.C., D.X., F.H. and Q.H. performed the experiments. L.P., J.J., Y.P. and C.Y. analyzed the data. R.F. and D.-L.H. supervised the study and designed the experiments. L.P., J.J., R.F. and D.-L.H. drafted the manuscript. All authors have read and agreed to the published version of the manuscript.

Funding: This study was supported by the National Key Research and Development Program of China (2018YFD0500500), the National Natural Science Foundation of China (31902256), the Foundation for Innovation Research Group in Chongqing Universities (CXQT20004), and the earmarked fund for China Agriculture Research System (CARS37).

Institutional Review Board Statement: The study was conducted according to the guidelines of the Declaration of Helsinki, and approved by Institutional Animal Care and Use Committee of Southwest University (Permit No. IACUC-2018-1025-01, 25 October 2018).

Informed Consent Statement: Not applicable.

Data Availability Statement: All the data generated for this study are included in the article.

Acknowledgments: We thank Feng Shao from NIBS (National Institute of Biological Sciences, Beijing) for providing the Caspase- $1^{-/-}$and $\mathrm{ASC}^{-/-}$mice.

Conflicts of Interest: The authors declare no conflict of interest. The funders had no role in the design of the study; in the collection, analyses, or interpretation of data; in the writing of the manuscript, or in the decision to publish the results.

\section{References}

1. Hu, D.L.; Omoe, K.; Sasaki, S.; Sashinami, H.; Sakuraba, H.; Yokomizo, Y.; Shinagawa, K.; Nakane, A. Vaccination with nontoxic mutant toxic shock syndrome toxin 1 protects against Staphylococcus aureus infection. J. Infect. Dis. 2003, 188, 743-752. [CrossRef]

2. Verhegghe, M.; Pletinckx, L.J.; Crombe, F.; Van Weyenberg, S.; Haesebrouck, F.; Butaye, P. Heyndrickx, M.; Rasschaert, G. Cohort study for the presence of livestock-associated MRSA in piglets: Effect of sow status at farrowing and determination of the piglet colonization age. Vet. Microbiol. 2013, 162, 679-686. [CrossRef]

3. Miles, G.; Movileanu, L.; Bayley, H. Subunit composition of a bicomponent toxin: Staphylococcal leukocidin forms an octameric transmembrane pore. Protein Sci. 2002, 11, 894-902. [CrossRef] [PubMed]

4. Flores-Díaz, M.; Monturiol-Gross, L.; Naylor, C.; Alape-Girón, A.; Flieger, A. Bacterial Sphingomyelinases and Phospholipases as Virulence Factors. Microbiol. Mol. Biol. Rev. 2016, 80, 597-628. [CrossRef] [PubMed]

5. Hennekinne, J.A.; De Buyser, M.L.; Dragacci, S. Staphylococcus aureus and its food poisoning toxins: Characterization and outbreak investigation. FEMS Microbiol. Rev. 2012, 36, 815-836. [CrossRef] [PubMed]

6. Todd, J.; Fishaut, M.; Kapral, F.; Welch, T. Toxic-shock syndrome associated with phage-group-I Staphylococci. Lancet 1978, 2, 1116-1118. [CrossRef]

7. Manders, S.M. Toxin-mediated streptococcal and staphylococcal disease. J. Am. Acad. Dermatol. 1998, 39, 383-398. [CrossRef]

8. Rasheed, J.K.; Arko, R.J.; Feeley, J.C.; Chandler, F.W.; Thornsberry, C.; Gibson, R.J.; Cohen, M.L.; Jeffries, C.D.; Broome, C.V. Acquired ability of Staphylococcus aureus to produce toxic shock-associated protein and resulting illness in a rabbit model. Infect. Immun. 1985, 47, 598-604. [CrossRef]

9. Grumann, D.; Ruotsalainen, E.; Kolata, J.; Kuusela, P.; Järvinen, A.; Kontinen, V.P.; Bröker, B.M.; Holtfreter, S. Characterization of infecting strains and superantigen-neutralizing antibodies in Staphylococcus aureus bacteremia. Clin. Vaccine Immunol. 2011, 18, 487-493. [CrossRef]

10. Fleischer, B.; Schrezenmeier, H. T cell stimulation by staphylococcal enterotoxins. Clonally variable response and requirement for major histocompatibility complex class II molecules on accessory or target cells. J. Exp. Med. 1988, 167, 1697-1707. [CrossRef]

11. Stich, N.; Waclavicek, M.; Model, N.; Eibl, M.M. Staphylococcal Superantigen (TSST-1) Mutant Analysis Reveals that T Cell Activation Is Required for Biological Effects in the Rabbit Including the Cytokine Storm. Toxins 2010, 2, 2272-2288. [CrossRef] [PubMed] 
12. Luhm, J.; Kirchner, H.; Rink, L. One-Way Synergistic Effect of Low Superantigen Concentrations on Lipopolysaccharide-Induced Cytokine Production. J. Interferon Cytokine Res. 1997, 17, 229-238. [CrossRef]

13. Beezhold, D.H.; Best, G.K.; Bonventre, P.F.; Thompson, M. Endotoxin Enhancement of Toxic Shock Syndrome Toxin I-Induced Secretion of Interleukin 1 by Murine Macrophages. Rev. Infect. Dis. 1989, 11 (Suppl. 1), S289-S293. [CrossRef]

14. Beezhold, D.H.; Best, G.K.; Bonventre, P.F.; Thompson, M. Synergistic induction of interleukin-1 by endotoxin and toxic shock syndrome toxin-1 using rat macrophages. Infect. Immun. 1988, 55, 2865-2869. [CrossRef]

15. Rossi, R.J.; Guruprasaadh, M.; Maxwell, J.R.; Vella, A.T. Staphylococcal enterotoxins condition cells of the innate immune system for Toll-like receptor 4 stimulation. Int. Immunol. 2004, 16, 1751-1760. [CrossRef] [PubMed]

16. Broz, P.; Dixit, V.M. Inflammasomes: Mechanism of assembly, regulation and signalling. Nat. Rev. Immunol. 2016, 16, 407-420. [CrossRef] [PubMed]

17. Tsuchiya, K.; Hara, H. The inflammasome and its regulation. Crit. Rev. Immunol. 2014, 34, 41-80. [CrossRef]

18. Zhao, Y.; Yang, J.; Shi, J.; Gong, Y.N.; Lu, Q.; Xu, H.; Liu, L.; Shao, F. The NLRC4 inflammasome receptors for bacterial flagellin and type III secretion apparatus. Nature 2011, 477, 596-600. [CrossRef]

19. Sauer, J.D.; Witte, C.E.; Zemansky, J.; Hanson, B.; Lauer, P.; Portnoy, D.A. Listeria monocytogenes triggers AIM2-mediated pyroptosis upon infrequent bacteriolysis in the macrophage cytosol. Cell Host Microbe 2010, 7, 412-419. [CrossRef]

20. Reyes Ruiz, V.M.; Ramirez, J.; Naseer, N.; Palacio, N.M.; Siddarthan, I.J.; Yan, B.M.; Boyer, M.A.; Pensinger, D.A.; Sauer, J.D.; Shin, S. Broad detection of bacterial type III secretion system and flagellin proteins by the human NAIP/NLRC4 inflammasome. Proc. Natl. Acad. Sci USA 2017, 114, 13242-13247. [CrossRef]

21. Fang, R.; Uchiyama, R.; Sakai, S.; Hara, H.; Tsutsui, H.; Suda, T.; Mitsuyama, M.; Kawamura, I.; Tsuchiya, K. ASC and NLRP3 maintain innate immune homeostasis in the airway through an inflammasome-independent mechanism. Mucosal Immunol. 2019, 12, 1092-1103. [CrossRef] [PubMed]

22. Fang, R.; Du, H.; Lei, G.; Liu, Y.; Feng, S.; Ye, C.; Li, N.; Peng, Y. NLRP3 inflammasome plays an important role in caspase-1 activation and IL-1 $\beta$ secretion in macrophages infected with Pasteurella multocida. Vet. Microbiol. 2019, 231, 207-213. [CrossRef] [PubMed]

23. Zhou, Z.; Li, H.; Tian, S.; Yi, W.; Zhou, Y.; Yang, H.; Li, X.; Wu, B.; Li, X.; Wu, J.; et al. Critical roles of NLRP3 inflammasome in IL-1 $\beta$ secretion induced by Corynebacterium pseudotuberculosis in vitro. Mol. Immunol. 2019, 116, 11-17. [CrossRef] [PubMed]

24. McGilligan, V.E.; Gregory-Ksander, M.S.; Li, D.; Moore, J.E.; Hodges, R.R.; Gilmore, M.S.; Moore, T.C.; Dartt, D.A. Staphylococcus aureus activates the NLRP3 inflammasome in human and rat conjunctival goblet cells. PLoS ONE 2013, 8, e74010. [CrossRef] [PubMed]

25. Wu, J.; Liu, B.; Mao, W.; Feng, S.; Yao, Y.; Bai, F.; Shen, Y.; Guleng, A.; Jirigala, B.; Cao, J. Prostaglandin E2 Regulates Activation of Mouse Peritoneal Macrophages by Staphylococcus aureus through Toll-Like Receptor 2, Toll-Like Receptor 4, and NLRP3 Inflammasome Signaling. J. Innate Immun. 2020, 12, 154-169. [CrossRef]

26. Huang, M.T.; Taxman, D.J.; Holleyguthrie, E.A.; Moore, C.B.; Willingham, S.B.; Madden, V.; Parsons, R.K.; Featherstone, G.L.; Arnold, R.R.; O'Connor, B.P.; et al. Critical role of apoptotic speck protein containing a caspase recruitment domain (ASC) and NLRP3 in causing necrosis and ASC speck formation induced by Porphyromonas gingivalis in human cells. J. Immunol. 2009, 182, 2395-2404. [CrossRef]

27. Lu, A.; Magupalli, V.G.; Ruan, J.; Yin, Q.; Egelman, E.H. Unified Polymerization Mechanism for the Assembly of ASC-Dependent Inflammasomes. Cell 2014, 156, 1193-1206. [CrossRef]

28. Wang, X.; Eagen, W.J.; Lee, J.C. Orchestration of human macrophage NLRP3 inflammasome activation by Staphylococcus aureus extracellular vesicles. Proc. Natl. Acad. Sci. USA 2020, 117, 3174-3184. [CrossRef]

29. Xiao, T.S. The nucleic acid-sensing inflammasomes. Immunol. Rev. 2015, 265, 103-111. [CrossRef]

30. Holzinger, D.; Gieldon, L.; Mysore, V.; Nippe, N.; Taxman, D.J.; Duncan, J.A.; Broglie, P.M.; Marketon, K.; Austermann, J.; Vogl, T.; et al. Staphylococcus aureus Panton-Valentine leukocidin induces an inflammatory response in human phagocytes via the NLRP3 inflammasome. J. Leukoc. Biol. 2012, 92, 1069-1081. [CrossRef]

31. Kebaier, C.; Chamberland, R.R.; Allen, I.C.; Gao, X.; Broglie, P.M.; Hall, J.D.; Jania, C.; Doerschuk, C.M.; Tilley, S.L.; Duncan, J.A. Staphylococcus aureus $\alpha$-hemolysin mediates virulence in a murine model of severe pneumonia through activation of the NLRP3 inflammasome. J. Infect. Dis. 2012, 205, 807-817. [CrossRef] [PubMed]

32. Tuffs, S.W.; James, D.B.A.; Bestebroer, J.; Richards, A.C.; Goncheva, M.I.; O'Shea, M.; Wee, B.A.; Seo, K.S.; Schlievert, P.M.; Lengeling, A.; et al. The Staphylococcus aureus superantigen SElX is a bifunctional toxin that inhibits neutrophil function. PLoS Pathog. 2017, 13, e1006461. [CrossRef] [PubMed]

33. Narita, K.; Hu, D.L.; Asano, K.; Nakane, A. Vaccination with non-toxic mutant toxic shock syndrome toxin-1 induces IL-17dependent protection against Staphylococcus aureus infection. Pathog. Dis. 2015, 73, ftv023. [CrossRef] [PubMed]

34. Cui, J.C.; Hu, D.L.; Lin, Y.C.; Qian, A.D.; Nakane, A. Immunization with glutathione S-transferase and mutant toxic shock syndrome toxin 1 fusion protein protects against Staphylococcus aureus infection. FEMS Immunol. Med. Microbiol. 2005, 45, 45-51. [CrossRef]

35. Le Feuvre, R.A.; Brough, D.; Iwakura, Y.; Takeda, K.; Rothwell, N.J. Priming of macrophages with lipopolysaccharide potentiates P2X7-mediated cell death via a caspase-1-dependent mechanism, independently of cytokine production. J. Biol. Chem. 2002, 277, 3210-3218. [CrossRef] 